(2) Open Access Full Text Article

REVIEW

\title{
Imaging-guided hyperstimulation analgesia in low back pain
}

This article was published in the following Dove Press journal:

Journal of Pain Research

24 June 2013

Number of times this article has been viewed

\author{
Miguel Gorenberg',2 \\ Kobi Schwartz ${ }^{3}$ \\ 'Department of Nuclear Medicine, \\ B'nai Zion Medical Center, Haifa, \\ Israel; ${ }^{2}$ The Rappaport Faculty \\ of Medicine, Technion - Israel \\ Institute of Technology, Haifa, Israel; \\ ${ }^{3}$ Department of Physical Therapy, B'nai \\ Zion Medical Center, Haifa, Israel
}

\begin{abstract}
Low back pain in patients with myofascial pain syndrome is characterized by painful active myofascial trigger points (ATPs) in muscles. This article reviews a novel, noninvasive modality that combines simultaneous imaging and treatment, thus taking advantage of the electrodermal information available from imaged ATPs to deliver localized neurostimulation, to stimulate peripheral nerve endings (A $\delta$ fibers) and in turn, to release endogenous endorphins. "Hyperstimulation analgesia" with localized, intense, low-rate electrical pulses applied to painful ATPs was found to be effective in $95 \%$ patients with chronic nonspecific low back pain, in a clinical validation study.
\end{abstract}

Keywords: myofascial, noninvasive, electrical, impedance

\section{Introduction}

Low back pain (LBP) is one of the most common complaints in the Western society. ${ }^{1,2}$ Ninety percent of the population in the United States suffer from low back pain at one or multiple points in time in their lifetime. ${ }^{2}$

Although LBP is a common chronic pain syndrome, in most cases a specific diagnosis cannot be established. It can arise due to spinal injury, spinal disc problems, osteoarthritis, spinal stenosis, compression fractures, spinal tumors, etc. ${ }^{3}$

Nonsteroidal anti-inflammatory drugs (NSAIDS) are generally used for acute LBP. Opioids are the alkaloid analgesics used for the treatment of moderate to severe pain syndromes. These opioids work on the $\mu, \kappa$, and $\alpha$ receptors in the central nervous system; ${ }^{4}$ however, due to the wide presence of these receptors in the body, opioids not only suppress the noxious stimuli effects, but also have undesirable side effects. ${ }^{5,6}$ The concerns arising from the use of analgesic medications have increased the interest in nonpharmacological therapies for LBP. Nonpharmacological treatment modalities for pain relief include heat, cold, acupuncture, electrotherapy, and massage. ${ }^{7}$ The use of cold and hot methods has been shown to cause tissue and nerve injury. ${ }^{8-10}$ Among the electrotherapy modalities are transcutaneous electrical nerve stimulation (TENS) with various pulse modulation, electroacupuncture, and percutaneous electrical nerve stimulation (PENS). ${ }^{11-13}$ Unfortunately, these modalities go amiss with respect to their provided duration and magnitude of analgesia. Study of TENS has produced results with limited statistical significance, ${ }^{14}$ and the American Academy of Neurology has advised against the use of TENS in chronic LBP, stating that the strongest evidence indicates that it is ineffective for this syndrome. ${ }^{15}$
Correspondence: Miguel Gorenberg Department of Nuclear Medicine, Bnai Zion Medical Centre, Golomb 47 haifa-Israel Email miguel.gorenberg@b-zion.org.il 
One accepted explanation for LBP symptoms is that patients have myofascial pain syndrome, a condition characterized by painful active myofascial trigger points (ATPs) in muscles. ${ }^{16,17}$

\section{ATP pathophysiology}

In the last $10-15$ years, much clinical and basic science research into ATPs has been published, including epidemiological, diagnostic, therapeutic, and pathophysiological studies. ${ }^{17-21}$ The pathogenesis of ATPs is probably related to sensitized sensory peripheral free nerve endings (nociceptors) associated with dysfunctional endplates. ${ }^{16}$ In a histological study, small nerve fibers were commonly found near the sensitive ATPs. ${ }^{22}$ Therefore, the sensitive loci in the region of muscle ATPs are probably related to sensitized nerve fibers (nociceptors).

Local pain could be explained by the tissue ischemia resulting from prolonged muscle contraction, with accumulation of acids and chemicals such as serotonin, histamine, kinins, and prostaglandins. ${ }^{23}$

Studies have suggested that the development of ATPs is dependent on an integrative mechanism in the spinal cord. When the input from the nociceptors in an original receptive field (pain from ATPs) persists, central sensitization in the spinal cord may develop, and the receptive field corresponding to the original dorsal horn neuron may be expanded (referred pain). Through this mechanism, new "satellite ATPs" may develop in the referred zone of the original ATPs. ${ }^{16}$

\section{"Hyperstimulation analgesia" of ATPs}

Common treatments of ATPs typically include minimally invasive intervention, such as injections with local anesthetics, corticosteroids, botulinum toxin, or dry needling. ${ }^{24}$ Serious complications, although of rare occurrence, have been reported (eg, pneumothorax, hematoma, intravascular injection of local anesthetics, and intrathecal injections). ${ }^{25}$

"Hyperstimulation analgesia" is an alternative modality, in which localized, intense, low-rate electrical pulses are applied to small surface areas at ATP locations to stimulate peripheral nerve endings (A $\delta$ fibers), thus causing the release of endogenous endorphins. ${ }^{26,27}$ Hyperstimulation anesthesia has been investigated in several controlled studies, showing a positive response in $87 \%$ of patients. ${ }^{26,28-30}$ Considerable evidence suggests that this type of neurostimulation analgesia is achieved through the activation of extra-segmental antinociceptive mechanisms, which accelerate the release of endogenous endorphins, serotonin, and cortisol..$^{27,31-34}$

\section{Identification of ATPs}

While the most common physical finding of ATPs has been considered the palpation of a hypersensitive nodule of muscle fiber of harder-than-normal consistency, the identification of such nodule appears to be very dependent on the subjective experience of the physician. There is no accepted reference standard for the clinical diagnosis of ATPs, and data on the reliability of physical examination are conflicting, and a 2009 review of nine studies examining the reliability of ATP diagnosis found that physical examination could not be recommended as reliable for the diagnosis of ATPs. ${ }^{24}$ Attempts to confirm the presence of myofascial trigger points using magnetic resonance elastography have been described. ${ }^{35}$ Recently, Sikdar et al have tried to use ultrasound to visualize and characterize ATPs. ${ }^{36}$ They found that ATPs appeared as focal, hypoechoic regions of elliptical shape, with a size of $0.16 \mathrm{~cm} .{ }^{36}$

The presence of ATPs causes a localized decrease in skin resistance compared with the surrounding area..$^{37,38}$ The hypoxic state in the pain area increases nociceptors and other sensitizing substances in the area, and this biochemical change induces greater blood flow and secretion from sweat glands, via stimulation of the autonomic nervous system. ${ }^{39}$ These physiologic differences may account for acute variations in electrodermal measurements at the pathologic site. ATPs are defined as small-diameter (3-4 mm), circumscribed, low-skin-resistance areas. ${ }^{38}$ Localized decrease in skin resistance is frequently associated with clinical ATPs that are richly innervated by myelinated $A \delta$ fibers ${ }^{40,41}$ the smallest in diameter $(0.2-1.5 \mu \mathrm{m})$ and most commonly present myelinated axons in peripheral nerves. Their extremely small size prevents their identification by any imaging modality. ${ }^{38}$

Electrical skin impedance measurements are considered to be vulnerable to certain sources of imprecision, including instrument error resulting from the size, pressure, and the duration of probe application as well as from local skin conditions, such as variable thickness, hydration, and integrity of the stratum corneum..$^{38,42}$

\section{Auto-targeting hyperstimulation of painful ATPs}

The hyperstimulation analgesia procedure is not extensively utilized in the clinical setting due to the necessity of locating appropriate ATPs. This necessity requires previous knowledge of the potential locations and the identification of ATPs associated with LBP and makes such treatments time consuming and cumbersome. ${ }^{26-28}$ Some devices offer the capability of measuring skin impedance for the location of 


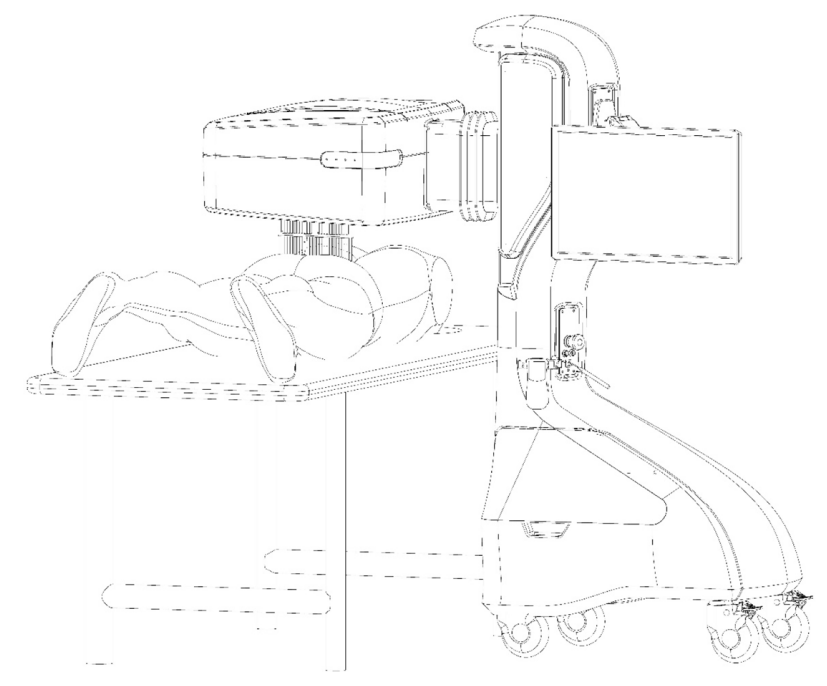

Figure I A novel automated robotic system, the Soleve ${ }^{\mathrm{TM}}$ (Nervomatrix Ltd, Netanya, Israel).

Notes: A moving row of 26 miniature pulsing probes gently touch but don't penetrate the skin's surface for the purposes of impedance mapping, which is then followed by the application of concentrated stimulating pulses.

ATPs, with the aim of applying hyperstimulation to them; ${ }^{43}$ however these are manually held devices that prolong the procedure, by firstly allowing application of hyperstimulation to a single point and secondly, by offering limited accuracy (due to their measurement of a single point at a time) that does not take advantage of the electrodermal information of the entire region of interest.

A novel automated robotic system, the Soleve ${ }^{\mathrm{TM}}$ (Nervomatrix Ltd, Netanya, Israel) (Figure 1), utilizes an array of miniature probes (Figure 2), allowing the measurement of skin impedance over the back at 1000 points in less than a couple of minutes. ${ }^{44}$ The system visualizes and analyzes the data to locate areas of low impedance compared with surrounding areas, thus indicating ATPs appropriate for hyperstimulation (Figure 3). Therapeutic neurostimulation, using modulated, intense electrical pulses, is then applied locally to specific painful ATPs, providing highly effective pain relief by stimulating the release of endorphins. ${ }^{31-34}$

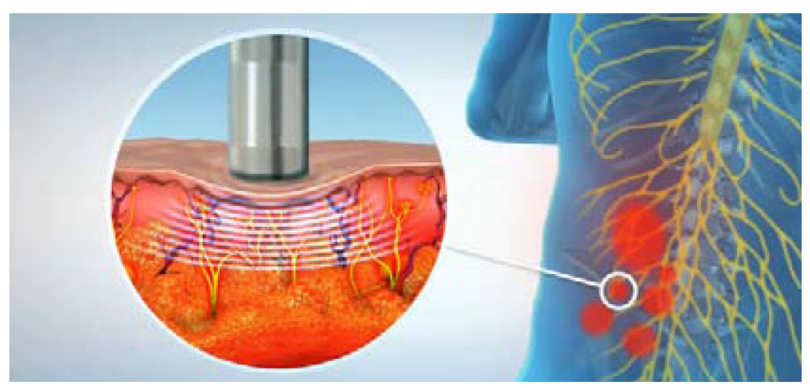

Figure 2 The new modality maps the lower back by measuring the electrical resistance of the skin at 1000 points in less than a couple of minutes.

Courtesy Ori Kanner, Nervomatrix Ltd.

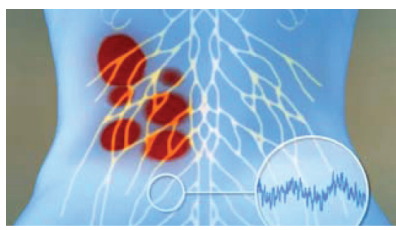

High impedance area

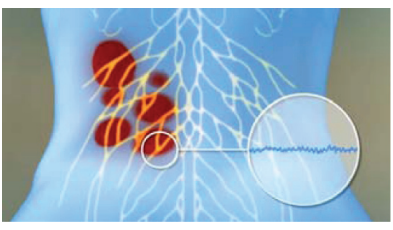

Decreased impedance area
Figure 3 Computer imaging is used to analyze the data, to identify the lowest points of electrical resistance and to select the areas for therapeutic stimulation. Courtesy, Ori Kanner, Nervomatrix Ltd.

\section{Clinical validation}

The effectiveness of the Soleve ${ }^{\mathrm{TM}}$ system was investigated in 19 patients diagnosed with nonspecific chronic LBP. ${ }^{44}$ Fifteen of the patients were female (79\%), and four were men $(21 \%)$, with a mean age of $52.1 \pm 10.8$ years. The protocol consisted of six treatment sessions, 2-4 days apart. Each session included a $<1$-minute, automatic impedance screening, followed by a 20 -minute treatment. The primary outcome measurement consisted of changes in pain intensity, as measured on a $100 \mathrm{~mm}-$ long pain visual analog scale (VAS) obtained at enrollment, pre-, and 2 hours posttreatment. The mean \pm standard deviation (SD) baseline VAS score for all patients was $61 \pm 14 \mathrm{~mm}$ (Figure 4). Following treatment, VAS scores decreased by $39 \pm 17 \mathrm{~mm}(P<0.001)$ compared with the baseline scores. Notably, the VAS scores of all but one patient decreased by more than $20 \mathrm{~mm}$ after the fourth treatment, representing a marked improvement in $95 \%$ of enrolled patients.

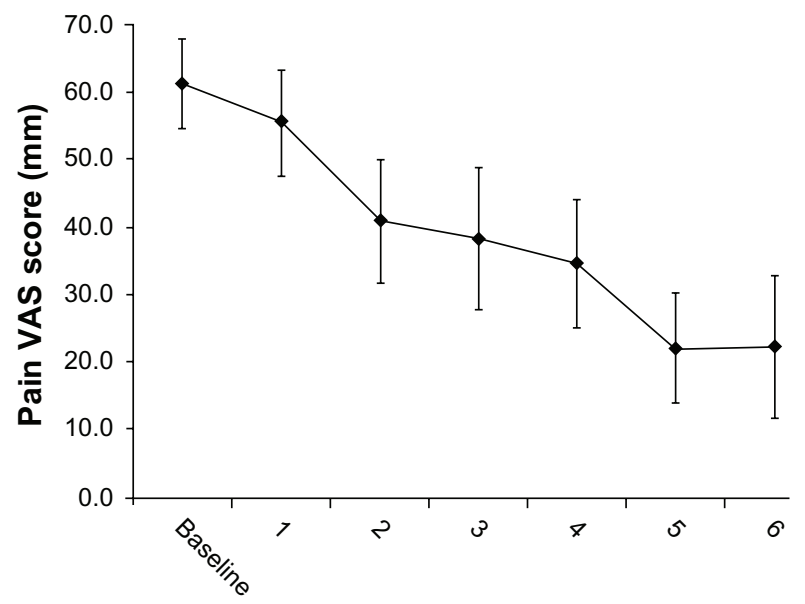

Number of treatments

Figure 4 Pain VAS scores.

Notes: The mean \pm SD baseline VAS score for the 19 participants was $61 \pm 14 \mathrm{~mm}$ During treatment, the VAS scores decreased significantly compared with baseline scores, by $39 \pm 17 \mathrm{~mm}(P<0.00 \mathrm{I})$. Notably, the VAS scores of all the patients except for one decreased by more than $20 \mathrm{~mm}$ after the second treatment, thus showing marked improvement in $95 \%$ of enrolled patients. Courtesy from Gorenberg M, Schiff E, Schwartz K, Eizenberg E. A novel image-guided, automatic, high-intensity neurostimulation device for the treatment of nonspecific low back pain. Pain Res Treat. 201 I;20I I:152307.44

Abbreviations: SD, standard deviation; VAS, visual analog scale. 


\section{Conclusion}

A novel, noninvasive, image-guided, targeted neurostimulation modality that combines impedance imaging to locate ATPs and treatment based on the image analysis was found very effective clinically in $95 \%$ of patients after a series of four treatments. This promising result warrants future investigation and randomized, controlled, longitudinal studies in the treatment of LBP.

\section{Acknowledgment}

This paper was supported by a grant from Nervomatrix, Israel.

\section{Disclosure}

Dr Gorenberg is a stockholder at Nervomatrix, Israel. The authors report no other conflicts of interest in this work.

\section{References}

1. Katz RT. Impairment and disability rating in low back pain. Phys Med Rehabil Clin N Am. 2001;12(3):681-694.

2. Steenstra IA, Anema JR, van Tulder MW, Bongers PM, de Vet HC, van Mechelen W. Economic evaluation of a multi-stage return to work program for workers on sick-leave due to low back pain. $J$ Occup Rehabil. 2006;16(4):557-578.

3. Atlas SJ, Deyo RA. Evaluating and managing acute low back pain in the primary care Setting. J Gen Intern Med. 2001;16(2):120-131.

4. Pappagallo M. Aggressive pharmacologic treatment of pain. Rheum Dis Clin North Am. 1999;25(1):193-213.

5. Rainsford KD. Profile and mechanisms of gastrointestinal and other side effects of nonsteroidal anti-inflammatory drugs (NSAIDs). Am J Med. 1999;107(6A):27S-35S

6. Furlan AD, Sandoval JA, Mailis-Gagnon A, Tunks E. Opioids for chronic noncancer pain: a meta-analysis of effectiveness and side effects. CMAJ. 2006;174(11):1589-1594.

7. Godfrey H. Understanding pain, part 2: pain management. Br J Nurs. 2005;14(17):904-909.

8. McLean DA. The use of cold and superficial heat in the treatment of soft tissue injuries. Br J Sports Med. 1989;23(1):53-54.

9. Ochoa JL, Yarnitsky D. The triple cold syndrome. Cold hyperalgesia, cold hypoaesthesia and cold skin in peripheral nerve disease. Brain. 1994;117(Pt 1):185-197.

10. Sluka K, Walsh D. Transcutaneous electrical nerve stimulation: basic science mechanisms and clinical effectiveness. J Pain. 2003;4(3): $109-121$.

11. Ghoname EA, Craig WF, White PF, et al. Percutaneous electrical nerve stimulation for low back pain: a randomized crossover study. JAMA. 1999;28(9):818-823.

12. Ghoname ES, Craig WF, White PF, et al. The effect of stimulus frequency on the analgesic response to percutaneous electrical nerve stimulation in patients with chronic low back pain. Anesth Analg. 1999;88(4):841-846.

13. Hamza MA, Ghoname EA, White PF, et al. Effect of the duration of electrical stimulation on the analgesic response in patients with low back pain. Anesthesiology. 1999;91(6):1622-1627.

14. Khadilkar A, Odebiyi DO, Brosseau L, Wells GA. Transcutaneous electrical nerve stimulation (TENS) versus placebo for chronic low-back pain [review]. Cochrane Database Syst Rev. 2008;8(4): CD003008

15. Simons DG, Travell JG. Myofascial origins of low back pain. 1. Principles of diagnosis and treatment. Postgrad Med. 1983;73(2):66, 68-70, 73.
16. Simons DG, Travell JG. Myofascial origins of low back pain. Principles of diagnosis and treatment. Postgrad Med. 1983;73(2);66,68-70,73.

17. Simons DG, Hong CZ, Simons LS. Endplate potentials are common to midfiber myofacial trigger points. Am J Phys Med Rehabil. 2002;81(3): 212-222.

18. Simons DG, Travell JG, Simons LS. Travell and Simons' Myofascial Pain and Dysfunction: The Trigger Point Manual Vol 1. 2nd ed. Baltimore, MD: Williams \& Wilkins; 1999.

19. Simons DG, Travell JG, Simons LS. Travell \& Simon `s Myofascial Pain and Dysfunction: The trigger point manual. Vol 1, 2nd ed. Baltimore: Williams \& Wilkins;1999.

20. Simons DG. Myofascial trigger points: the critical experiment. J Musculoskelet Pain. 1997;5(4):111-118.

21. Simons DG. Diagnostic criteria of myofascial pain due to trigger points. J Musculoskelet Pain. 1999;7(1/2):111-120.

22. Hong CZ, Chen JT, Chen SM, Yan JJ, Su YJ. Histological findings of responsive loci in a myofascial trigger spot of rabbit skeletal muscle from where localized twitch responses could be elicited. Arch Phys Med Rehabil. 1996;77:962.

23. Travell J, Rinzler SH. The myofascial genesis of pain. Postgrad Med. 1952;11(5):425-434.

24. Lucas N, Macaskill P, Irwig L, Moran R, Bogduk N. Reliability of physical examination for diagnosis of myofascial trigger points: a systematic review of the literature. Clin J Pain. 2009;25(1):80-89.

25. Nelson LS, Hoffman RS. Intrathecal injection: unusual complication of trigger-point injection therapy. Ann Emerg Med. 1998;32(4):506-508.

26. Flowerdew MW, Gadsby JG. A review of the treatment of chronic low back pain with acupuncture-like transcutaneous electrical nerve stimulation and transcutaneous electrical nerve stimulation. Complementary Therapies in Medicine. 1997;5(4):193-201.

27. Sjölund B, Terenius L, Eriksson M. Increased cerebrospinal fluid levels of endorphins after electro-acupuncture. Acta Physiol Scand. 1977;100(3):382-384.

28. Cheng R, Pomeranz B. Electrotherapy of chronic musculoskeletal pain: comparison of electroacupuncture and acupuncture-like transcutaneous electrical nerve stimulation. Clin J Pain. 1986;2(3):143-150.

29. Cheng R, Pomeranz B. Electroacupuncture analgesia could be mediated by at least two pain-relieving mechanisms; endorphin and nonendorphin system. Life Sci. 1979;25(23):1957-1962.

30. Cheng R, McKibbin L, Roy B, Pomeranz B. Electroacupuncture elevates blood cortisol levels in naive horses; sham treatment has no effect. Int J Neurosci. 1980;10(2-3):95-97.

31. Bender T, Nagy G, Barma I, et al. The effect of physical therapy on beta-endorphin levels. European Journal of Applied Physiology Volume. 2007;100(4):371-38.

32. Sjölund BH, Eriksson MBE. Endorphins and analgesia produced by peripheral conditioning stimulation. Adv Pain Res Ther. 1979;3: 587-592.

33. Sjölund B, Eriksson M. Electro-acupuncture and endogenous endorphins. Lancet. 1976;308(7994):1085.

34. Hughes GS Jr, Lichstein PR, Whitlock D, Harker C. Response of plasma beta-endorphins to transcutaneous electric nerve stimulation in healthy subjects. Phys Ther. 1984;64(7):1062-1066.

35. Basford JR, An KN. New techniques for the quantification of fibromyalgia and myofascial pain. Curr Pain Headache Rep. 2009;13(5): 376-378.

36. Sikdar S, Shah JP, Gebreab T, et al. Novel applications of ultrasound technology to visualize and characterize myofascial trigger points and surrounding soft tissue. Arch Phys Med Rehabil. 2009;90(11): $1829-1838$.

37. Dommerholt J, Bron C, Franssen J. Myofascial trigger points: an evidence-informed review. J Man Manip Ther. 2006;14(4): 203-221.

38. Shultz SP, Driban JB, Swanik CB. The evaluation of electrodermal properties in the identification of myofascial trigger points. Arch Phys Med Rehabil. 2007;88(6):780-784.

39. Simons DG, Mense S. Understanding and measurement of muscle tone as related to clinical muscle pain. Pain. 1998;75(1):1-17. 
40. Dommerholt J. Dry needling in orthopedic physical therapy practice. Orthopaedic Practice. 2004;16(3):15-20.

41. Nakatani Y. A Guide for the Application of Ryodoraku Autonomous Nerve Regulatory Therapy. Alhambra, CA: Chan's Books and Products; 1972.

42. Inui K, Tran TD, Hoshiyama M, Kakigi R. Preferential stimulation of Adelta fibers by intra-epidermal needle electrode in humans. Pain. 2002;96(3):247-252.
43. Colbert A, Hammerschlag R, Aickin M, McNames J. Reliability of the Prognos electrodermal device for measurements of electrical skin resistance at acupuncture points. JAltern Complement Med. 2004;10(4): 610-616.

44. Gorenberg M, Schiff E, Schwartz K, Eizenberg E. A novel imageguided, automatic, high-intensity neurostimulation device for the treatment of nonspecific low back pain. Pain Res Treat. 2011;2011: 152307.

\section{Publish your work in this journal}

The Journal of Pain Research is an international, peer-reviewed, open access, online journal that welcomes laboratory and clinical findings in the fields of pain research and the prevention and management of pain. Original research, reviews, symposium reports, hypothesis formation and commentaries are all considered for publication.
Dovepress

The manuscript management system is completely online and includes a very quick and fair peer-review system, which is all easy to use. Visit http://www.dovepress.com/testimonials.php to read real quotes from published authors. 